ISSN 2466-2232

Online ISSN 2466-2100

\title{
$\mathrm{A} 319$ 알루미늄 합금 표면에 $\mathrm{Al}-36 \% \mathrm{Si}$ 합금분말의 레이저 클래딩에 의한 내마모성 향상
}

\author{
이 형 근,+十 \\ *한밭대학교 공과대학 신소재공학과
}

\section{Laser Cladding with Al-36\%Si Powder Paste on A319 Al Alloy Surface to Improve Wear Resistance}

\author{
Hyoung-Keun Lee*, \\ *Department of Advanced Materials Engineering, HanBat National University, Daejeon 34158, Korea \\ †Corresponding author : leehk@hanbat.ac.kr \\ (Received December 30, 2016 ; Revised February 14, 2017 ; Accepted February 27, 2017)
}

\begin{abstract}
A319 aluminum alloy containing $6.5 \% \mathrm{Si}$ and $3.5 \% \mathrm{Cu}$ as major alloying elements has been widely used in machinery parts because of its excellent castability and crack resistance. However it needs more wear resistance to extend its usage to the severe wear environments. It has been known that hyper-eutectic Al-Si alloy having more than $12.6 \% \mathrm{Si}$ contains pro-eutectic $\mathrm{Si}$ particles, which give better wear resistance and lubrication characteristics than hypo-eutectic Al-Si alloy like A319 alloy. In this study, it was tried to clad hyper-eutectic Al-Si alloy on the surface of A319 alloy. In the experiments, Al-36\%Si alloy powder was mixed with organic binder to make a fluidic paste. The paste was screen-printed on the A319 alloy surface, melted by pulsed Nd:YAG laser and alloyed with the A319 base alloy. As experimental parameters, the average laser power was changed to $111 \mathrm{~W}, 202 \mathrm{~W}$ and $280 \mathrm{~W}$. With increasing the average laser power, the melting depth was changed to $142 \mu \mathrm{m}, 205 \mu \mathrm{m}$ and $245 \mu \mathrm{m}$, and the dilution rate to $67.2 \%, 72.4 \%$ and $75.7 \%$ and the $\mathrm{Si}$ content in the cladding layer to $16.2 \%, 14.6 \%$ and $13.7 \%$, respectively. The cross-section of the cladding layer showed very fine eutectic microstructure even though it was hyper-eutectic Al-Si alloy. This seems to be due to the rapid solidification of the melted spot by single laser pulse. The average hardness for the three cladding layers was HV175, which was much higher than HV96 of A319 base alloy. From the block-on-roll wear tests, A319 alloy had a wear loss of $5.8 \mathrm{mg}$, but the three cladding layers had an average wear loss of $3.5 \mathrm{mg}$, which meant that an increase of $40 \%$ in wear resistance was obtained by laser cladding.
\end{abstract}

Key Words : Laser cladding, A319 Al alloy, Al-36\%Si powder, Microstructure, Micro-Vickers hardness, Wear resistance

\section{1. 서 론}

$\mathrm{Al}-\mathrm{Si}$ 합금은 경량이며, 주조성이 우수하여 공업용 부품의 제조에 많이 사용되어 왔다. 특히 A319 합금은 주조성과 내균열성이 우수하여 자동차, 기계 부품의 제 작에 광범위하게 사용되어 왔다 ${ }^{1)}$. A319 합금은 $6.5 \% \mathrm{Si}$, $3.5 \% \mathrm{Cu}$ 를 함유하고 있는 아공정(hypoeutectic) $\mathrm{Al}-\mathrm{Si}$
합금으로 실리콘 함량이 적어 응고시 균열의 위험은 적 으나, 내마모성이 떨어지는 단점이 있다. 내마모성을 증 가시키기 위해서는 실리콘 함량을 증가시켜야 하나, 실리 콘 함량이 공정조성 이상으로 증가하면 인성이 감소한다 2). A319 합금의 표면에 과공정(hypereutectic) $\mathrm{Al}-\mathrm{Si}$ 합금을 클래딩(cladding)하는 경우 기계적 특성과 내 마모성을 동시에 개선할 수 있다.

본 연구에서는 최근에 사용이 확장되고 있는 레이저 
클래딩 방법 ${ }^{3)}$ 을 사용하여 과공정 $\mathrm{Al}-\mathrm{Si}$ 합금 코팅층을 제작하고자 하였다. $\mathrm{Al}-36 \mathrm{Si}$ 합금분말을 유기용제와 혼 합하여 페이스트(paste)로 만들어, A319 모재 표면에 스크린 프린팅에 의해 도포하고, 레이저 주사(scanning) 에 의해 용융접합하였다. 이전에 $\mathrm{A} 1050 \mathrm{Al}$ 합금 표면 에 순수한 실리콘 분말을 사용하여 레이저 표면 합금화 시키는 연구를 수행하였다). 순수한 실리콘 분말을 사용 하는 경우 코팅층의 실리콘 함량의 변화가 레이저 출력 에 매우 민감하게 변화하였다. 본 연구에서는 순수한 실리콘 대신 $\mathrm{Al}-36 \mathrm{Si}$ 분말을 사용하여, 코팅층의 조성 이 레이저 출력에 다소 둔감하게 변하도록 시도하였다. 코팅층에 대해서는 경도시험과 마모시험을 수행하여 내 마모성의 향상을 관찰하였다.

\section{2. 실험방법}

\section{$2.1 \mathrm{Al}-36 \mathrm{Si}$ 분말 페이스트의 도포}

$\mathrm{A} 319$ 알루미늄 합금 모재는 $25 \times 45 \times 4.5 \mathrm{~mm}$ 의 치수로 절단하였다. 모재는 \#800 사포에서 연마 후 초 음파 세척하였다. $\mathrm{Al}-36 \mathrm{Si}$ 분말은 atomizing에 의해 제작하였으며, 화학조성은 $\mathrm{Al}, 36 \mathrm{wt} \% \mathrm{Si}$ 으로 분석되었 다. 분말은 sieve를 사용하여 $25 \sim 65 \mu \mathrm{m}$ 사이의 입자들 을 선별하여 사용하였다. 분말의 형상과 입도분포는 Fig. 1 에서 보여 준다.

$\mathrm{Al}-36 \mathrm{Si}$ 분말은 $\mathrm{PEG}$ 계의 유기용제와 혼합하여 페이 스트로 제작하였다. 페이스트는 두께 $0.1 \mathrm{~mm}$ 의 STS 메쉬 스크린(mesh screen)을 사용하여 합금 모재에 스 크린 프린팅 (screen printing)하였다. 메쉬 스크린은 $0.23 \times 1.1 \mathrm{~mm}$ 의 타원형 개구부들 사이에 $0.11 \mathrm{~mm}$ 의 STS만 남겨두고 에칭·식각하여 제작하였다. Al-36Si 페이스트 층은 $130{ }^{\circ} \mathrm{C}$ 에서 10 분간 가열하여 유기용제 는 증발시켰다. 남겨진 $\mathrm{Al}-36 \mathrm{Si}$ 분말들은 서로 결합되 어, 레이저 조사시 분말층을 그대로 유지할 수 있었다.

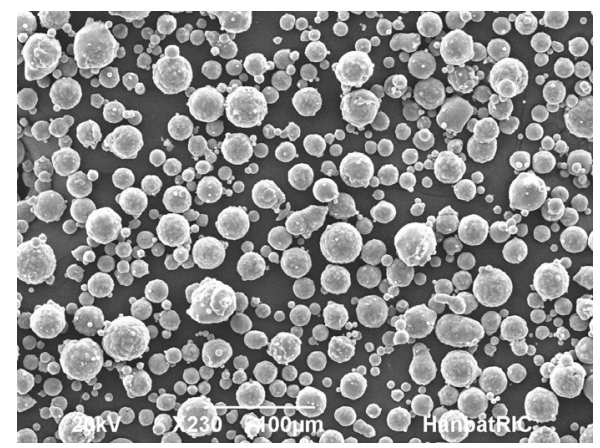

Fig. 1 Shape and size of Al-36Si powder

\section{2 레이저 조사에 의한 코팅층의 형성}

레이저는 파장 $1064 \mathrm{~nm}$, 최대출력 $400 \mathrm{~W}$ 를 가지는 펄스 펌핑형 $\mathrm{Nd}: \mathrm{YAG}$ 레이저를 사용하였다. 레이저 빔은 $600 \mu \mathrm{m}$ 의 광섬유(optical fiber)로 전송하였으며, 초점거리 $203 \mathrm{~mm}$ 의 집속렌즈를 사용하여 시편 표면에 집속시켰다. 시편의 표면은 산화방지를 위하여 $\mathrm{Ar}$ 보호가 스를 흘렸다.

실험변수로는 펄스 폭의 조절에 의해 레이저 평균출력 을 변화시켰다. 레이저의 출력조건은 Table 1 에 기술되 어 있다. 시편 \#1은 평균출력 $111 \mathrm{~W}$, 시편 \#2는 $201 \mathrm{~W}$, 시편 \#3는 $280 \mathrm{~W}$ 를 사용하였다.

레이저 초점을 표면에 위치시키고, 넓은 면적에 주사 (scanning)하였다. 주사속도는 $10 \mathrm{~mm} / \mathrm{s}$ 이며, 주사선 간격은 $0.5 \mathrm{~mm}$ 로 주사하였다. 요구되는 시편의 크기 에 따라 미세조직과 경도 분석을 위해서는 10 회 주사 하였으며, 마모시험을 위해서는 30회 주사하였다. 이때 초점에서 용융직경은 약 $1.17 \mathrm{~mm}$ 를 가졌다.

\section{3 미세조직 분석 및 마모시험 방법}

클래딩된 시편들은 횡단면을 절단하고, 마운팅(mounting) 한 후 경면연마(polishing)하였다. 시편들은 표면을 부 식(etching)하였으며, 주사전자현미경과 $\mathrm{EDX}$ 에 의해 미세조직과 화학조성을 분석하였다. 코팅층의 두께는 전 체 코팅층에 대하여 30 지점 이상 측정하여 평균값을 취하였다. 내마모성은 경도에 크게 의존하기 때문에 코 팅층의 미소 비커스(micro-Vickers) 경도를 측정하였다.

마모시험은 block-on-roll type을 사용하였다. Fig. 2 에서는 마모시험의 개략도를 보여 준다. 마모시험을 위하여 코팅층은 \#1200의 사포로 연마하여 표면요철을 모두 제거하였다. 상대 마모재로는 폭 $7 \mathrm{~mm}$, 직경 $50 \mathrm{~mm}$ 의 annealing된 상태의 SKD11 강으로 제작된 roll을 사용하였다. SKD11 강 역시 \#1200까지 연마한 후 마 모시험을 수행하였다. SKD11 강의 경도는 HRB 96 (HV 226)을 가졌다. 마모시험은 시편의 표면에 수직 하중 $0.95 \mathrm{~kg}$ 을 가하였으며, roll의 회전속도는 $500 \mathrm{rpm}$

Table 1 Laser irradiation conditions

\begin{tabular}{|l|c|c|c|}
\hline \multicolumn{1}{|r|}{ Specimen No. } & 1 & 2 & 3 \\
\hline Variable & \multicolumn{3}{|c|}{250} \\
\hline Pumping Voltage (V) & \multicolumn{3}{|c|}{50} \\
\hline Pulse Frequency (Hz) & 1.2 & 1.8 & 2.3 \\
\hline Pulse Width (ms) & 111 & 201 & 280 \\
\hline Average Power (W) & 2.2 & 4.0 & 5.6 \\
\hline Energy/Pulse (J) & 1.8 & 2.2 & 2.4 \\
\hline Intensity/pulse (kW/pulse) & & & \\
\hline
\end{tabular}




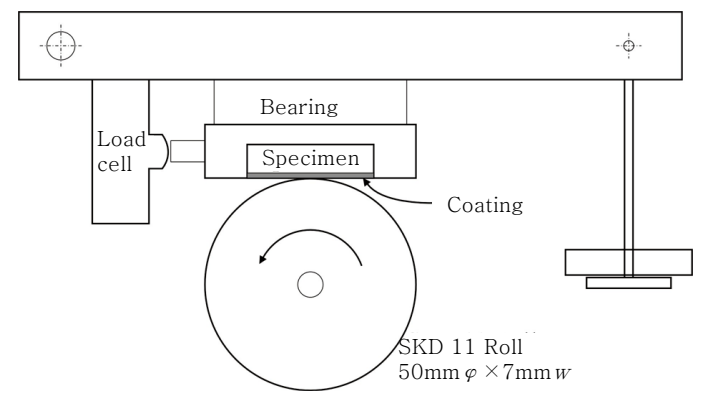

Fig. 2 Schematic diagram of a block-on-ring wear test

을 사용하였다. 이때 접촉 표면에서 마찰속도는 $1.3 \mathrm{~m} / \mathrm{s}$ 에 해당한다. $1.31 \mathrm{~km}$ 마모시킨 후 마모량을 측정하였 다. 마모량은 마모시험 전·후의 마모 손실량으로 측정하 였다. 마모시험 중에 data acquisition 장치를 사용하 여 마찰계수와 온도를 지속적으로 측정 기록하였다.

\section{3. 실험 결과 및 검토}

\section{1 코팅층 단면의 미세조직}

Fig. 3에서는 시편 \#1의 단면에 대한 주사전자현미 경 미세조직을 보여 준다. 미세조직은 부분적으로 용접 선을 따라 불균질성을 보이고 있으나, 코팅층의 두께는 비교적 고르게 형성되었다. 코팅층의 두께는 $142 \mu \mathrm{m}$ 이며, 희석율은 $67.2 \%$ 를 가졌다. 코팅층의 평균조성은 $\mathrm{Al}-$ $16.2 \% \mathrm{Si}$ 으로 과공정 $\mathrm{Al}-\mathrm{Si}$ 합금(공정조성: $12.6 \% \mathrm{Si}$ ) 에 해당하였다. 코팅층은 모재에 비하여 매우 미세한 조직을 가졌다. 코팅층의 매우 미세한 조직은 매 레이 저 펄스마다 순간적인 용융과 응고가 일어나서 응고속 도가 매우 빠르기 때문이다. 또한 일반적으로 과공정 합금에서 관찰되는 초정 실리콘은 거의 관찰되지 않았 으며, 대부분 매우 미세한 공정조직으로 이루어져 있었 다. Fig. 3(b)에서 기지조직은 알루미늄이며, 그물망 부분이 공정 실리콘 지역이다. 과공정 $\mathrm{Al}-\mathrm{Si}$ 합금임에 도 불구하고, 초정 실리콘이 거의 관찰되지 않는 것은 응고속도가 매우 빠르기 때문이다. 빠른 냉각속도에서 $\mathrm{Ai}-\mathrm{Si}$ 합금의 공정조성은 실리콘이 많은 쪽으로 이동한다 고 알려져 있으며 ${ }^{5,6)}$, 냉각속도가 매우 빠른 경우 30wt\%

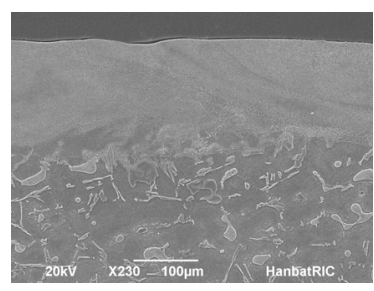

(a) general view

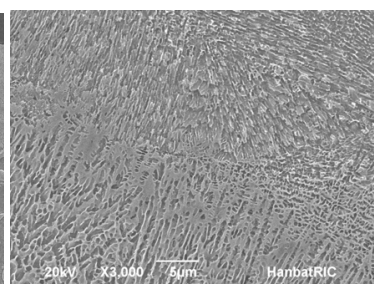

(b) magnified view
Fig. 3 Microstructure of the coating layer of specimen \#1(1.2 ms, $111 \mathrm{~W})$

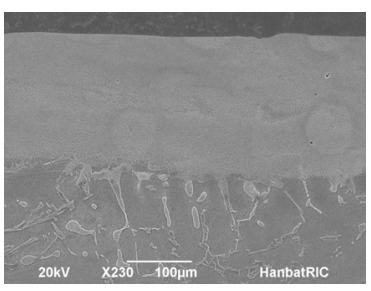

(a) $1.8 \mathrm{~ms}, 201 \mathrm{~W}$

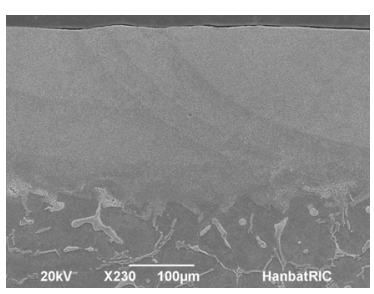

(b) $2.3 \mathrm{~ms}, 280 \mathrm{~W}$
Fig. 4 Microstructure of the coating layer of the specimen \#2(1.8 ms, $201 \mathrm{~W})$ and \#3(2.3 ms, $280 \mathrm{~W})$

$\mathrm{Si}$ 에까지 이동한다고 알려져 있다 ${ }^{7)}$.

시편 \#2의 전자현미경 미세조직은 Fig. 4(a)에서 보 여 준다. 코팅층의 두께는 $205 \mu \mathrm{m}$ 이며, 희석율은 $72.4 \%$ 로 측정되었으며, 평균조성은 $\mathrm{Al}-14.6 \% \mathrm{Si}$ 이다. 미세 조직은 매우 미세하며, 두께는 균일하게 형성되었다. $\mathrm{Si}$ 함량은 시편 \#1보다 약간 적으나 과공정 $\mathrm{Al}-\mathrm{Si}$ 합 금이기 때문에, 미세조직은 시편 \#1과 큰 차이가 없었다.

Fig. 4(b)에서는 시편 \#3의 미세조직을 보여 준다. 코팅층의 두께는 $245 \mu \mathrm{m}$ 이며, 희석율은 $75.7 \%$ 이며, 평균조성은 $\mathrm{Al}-13.7 \% \mathrm{Si}$ 로 역시 과공정을 유지하였다. 이 경우에도 시편 \#1보다 $\mathrm{Si}$ 함량이 약간 적으나 과공 정 조성을 유지하고 있어, 미세조직은 시편 \#1와 \#2과 유사하였다.

레이저 출력을 $111 \mathrm{~W}$ 에서 $280 \mathrm{~W}$ 로 비교적 크게 변 화시켰으나, $\mathrm{Si}$ 함량은 $16.2 \%$ 에서 $13.7 \%$ 로 큰 차이 를 나타내지 않았으며, 미세조직은 모두 매우 미세한 공정조직을 나타내었다.

\section{2 미소 비커스 경도 측정}

Fig. 5에서는 코팅층과 모재에 걸쳐서 미소경도 측정 결과를 보여 준다. 코팅층의 두께가 얇아서 그림에서처 럼 경사지게 경도를 측정하였다. 코팅층의 평균경도는 시편 \#1에서는 $\mathrm{HV} 177$, 시편 \#2는 $\mathrm{HV} 164$, 시편 \#3 은 $\mathrm{HV} 181$ 로 측정되었다. 같은 시편에서도 측정위치

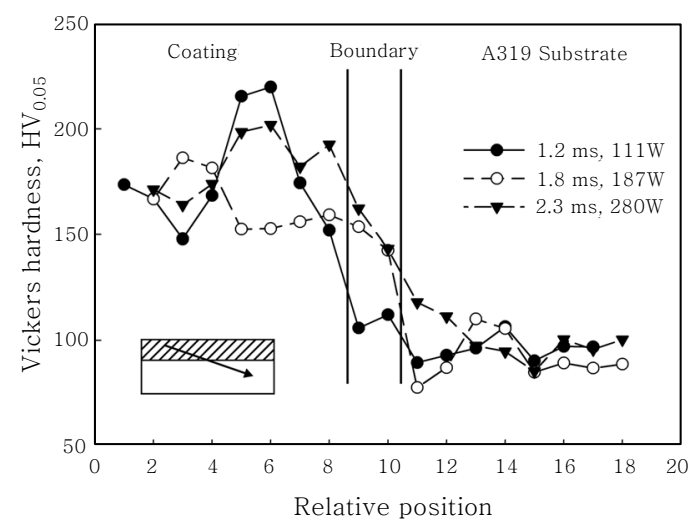

Fig. 5 Vickers hardness distribution across the boundary 
에 따라 미소경도가 $\mathrm{HV} 150$ $\mathrm{HV} 220$ 범위에서 크 게 변화하였다. 코팅층들 사이에 조성의 차이가 크지 않기 때문에 각 코팅층에 대한 경도 값의 구분은 큰 의 미를 가지지 않았다. 모든 코팅층들에 대한 평균경도는 $\mathrm{HV} 175$ 를 가졌다. A319 모재의 경우에도 측정위치에 따라 상당히 차이가 있었으나, $\mathrm{HV}$ 96의 평균경도를 가졌다. 코팅층의 경도는 모재에 비해 크게 증가하였다. 대표적인 과공정 $\mathrm{Al}-\mathrm{Si}$ 주물합금인 $\mathrm{A} 390(\mathrm{Al}-17 \% \mathrm{Si})$ ) 의 경우 열처리되지 않은 상태에서 약 HV 100, T6 열 처리한 경우 약 HV 140 의 경도 값을 가진다1). 이에 비해 코팅층들은 응고한 그대로의 상태에서 매우 높은 경도 값을 보여 준다.

\section{3 마모시험}

A319 모재와 클래딩된 시편들에 대한 마모시험 결과는 Table 2와 Fig. 6에서 보여 준다. 모재의 경우 $5.8 \mathrm{mg}$ 의 마모손실이 발생한 반면, 코팅층에서는 시편 \#1, \#2, \#3에서 각각 $3.4,3.8,3.3 \mathrm{mg}$ 의 마모손실이 발생하 였다. 레이저 출력에 따른 코팅층들 사이의 마모량의 차이는 크지 않았으며, 평균 $3.5 \mathrm{mg}$ 의 마모손실이 발 생하였다. 코팅층은 $\mathrm{A} 319$ 모재에 비해 평균 약 $40 \%$ 의 내마모성 증가가 발생하였다. Fig. 7에서는 마찰계 수를 측정한 결과를 보여 준다. 초기에는 마찰계수가 높으나, 마찰이 진행될수록 마찰계수가 낮아진다. 초기 마찰계수는 초기 접촉 상태와 다른 원인에 따라서 달라 진다. 따라서 $400 \mathrm{~m} \sim 1200 \mathrm{~m}$ 구간에서의 평균 마찰계 수를 측정하여 그림에 $(\mathrm{a}),(\mathrm{b}),(\mathrm{c}),(\mathrm{d})$ 로 나타내었다. A319 모재의 마찰계수는 0.444로 측정되었으며, 시편

Table 2 Wear loss after wear test

\begin{tabular}{|l|c|c|c|c|}
\hline Specimen & A319 & $\# 1$ & $\# 2$ & $\# 3$ \\
\hline Weight loss(mg) & 5.8 & 3.4 & 3.8 & 3.3 \\
\hline Scar depth(mm) & 0.102 & 0.071 & 0.077 & 0.070 \\
\hline
\end{tabular}

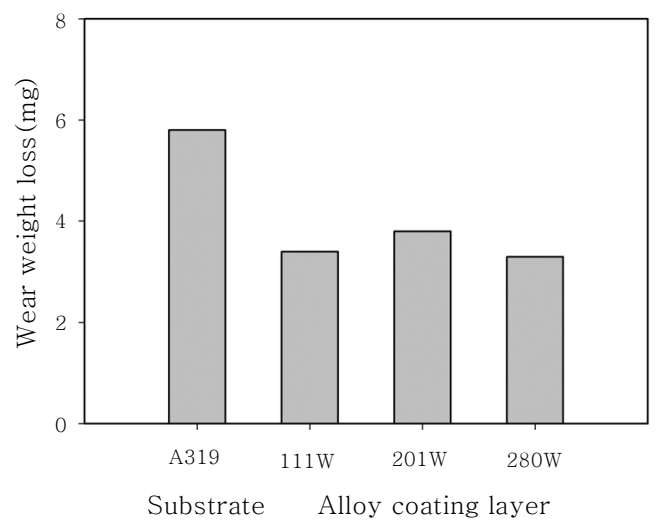

Fig. 6 Comparison of wear loss after wear test

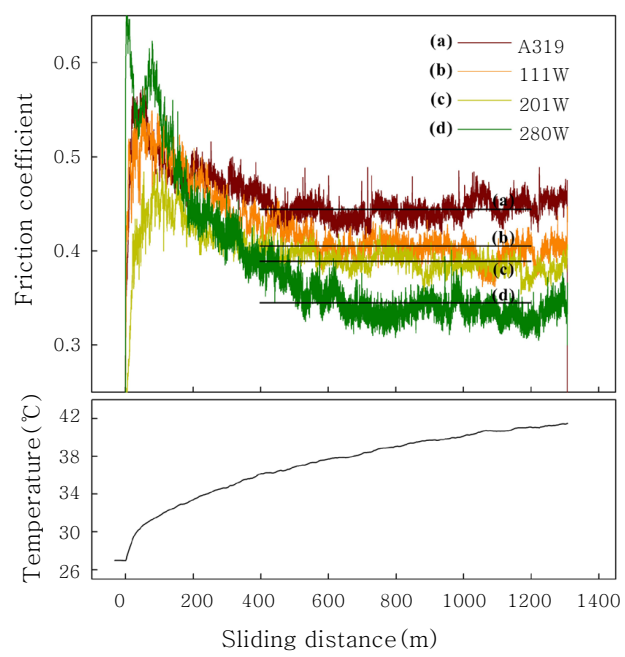

Fig. 7 Variation of friction coefficient and temperature near the friction interface with sliding distance

\#1에서는 0.405 , 시편 \#2는 0.389 , 시편 \#3는 0.345 로 측정되었다. A319 모재에 비해 모든 코팅층의 마찰 계수가 감소하였다.

Fig. 8에서는 A319 모재와 시편 \#2(1.8 ms, $201 \mathrm{~W})$ 의 마모시험 후 시험편(block)의 마모흔적(a)과 마모 부스러기(b)의 전자현미경 사진을 보여 준다. 다른 코 팅층들도 시편 \#2와 비슷하였다. A319 모재의 마모흔 적(Fig. 8(a))은 코팅층에 비해 다소 크다. 마모 부스 러기(Fig. 8(b))를 보면 A319 모재는 상당히 큰 판상 의 마모편들이 많았으나, 코팅층은 비교적 작은 판상 마모편들과 작은 마모 부스러기들이 많았다. A319 모 재에 비해 코팅층들의 마모편들이 작은 것은 접착마모 의 분율이 줄어든 때문으로 보인다.



A319 Substrate

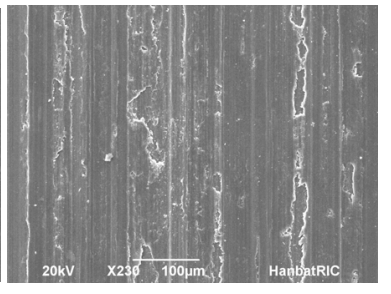

Coating, $201 \mathrm{~W}$

(a) Wear scar on the block side

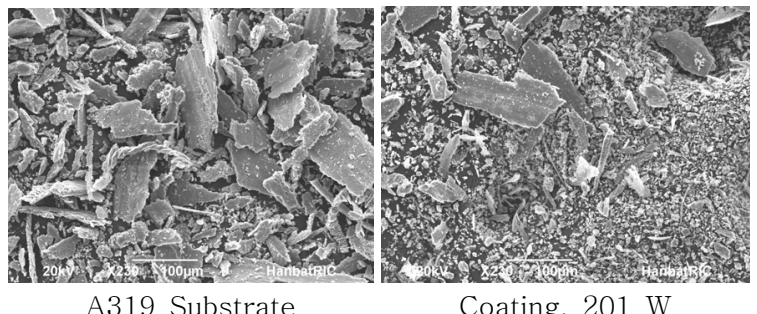

(b) Wear debris

Fig. 8 Wear scar and wear debris after wear test 


\section{4. 결 론}

본 연구에서는 $\mathrm{Al}-36 \mathrm{Si}$ 합금분말 페이스트를 $\mathrm{A} 319$ 모재 표면에 도포한 후, 펄스형 $\mathrm{Nd}: \mathrm{YAG}$ 레이저를 조 사하여 과공정 $\mathrm{Al}-\mathrm{Si}$ 코팅층을 형성하였다.

1) 평균출력 $111 \mathrm{~W}, 201 \mathrm{~W}, 280 \mathrm{~W}$ 로 조사하였 을 때, 실리콘 함량은 각각 $16.2 \%, 14.6 \%, 13.7 \%$ 를 가졌다. 레이저 조사에 의해 다른 공정에서 얻기 어 려운 매우 미세한 조직을 가졌다.

2) A319 모재의 경도는 HV 96이었다. 코팅에 의해 평균 HV 175 로 경도를 크게 증가시킬 수 있었다.

3) block-on-roll 마모시험에서 A319 모재에서는 $5.8 \mathrm{mg}$ 이, 코팅층에서는 평균 $3.5 \mathrm{mg}$ 의 마모손실이 발생하였다. A319 모재를 레이저 코팅하여 약 $40 \%$ 의 내마모성을 개선할 수 있었다. 마찰계수는 A319 모 재에서는 0.444 이었으나, 레이저 코팅에 의해 0.405 0.345로 감소하였다. A319 모재는 큰 판상의 마모 편들이 많았으나, 코팅층에서는 작은 판상 마모편들과 작은 부스러기 형태들이 관찰되었다.

\section{References}

1. J. R. Davis : Aluminium and Aluminium Alloys, ASM International, 1993, 532-541

2. S. Tomida, K. Nakata, S. Shibata, I. Zenkouji and S. Saji : Improvement on Wear Resistance of Hyper-eutectic AlSi Cast Alloy by Laser Surface Remelting, Surface \& Coatings Technology, 169-170 (2003), 468-471

3. H. K. Lee : Analysis and Optimization of the Cladding Parameters for Improving Deposition Efficiency in Cladding using a Low Power Pulsed Nd:YAG Laser, Journal of KWJS, 25 (4) (2007), 49-57 (in Korean)

4. H. K. Lee : Effects of Average Power on Laser Cladding of Hypereutectic Al-Si Alloy on Al 1050 Alloy, Journal of KWJS, 29 (2) (2011), 99-104 (in Korean)

5. A. Kamio : Structures and Properties of Aluminium, Japan Institute of Light Metals, (1991), 248-249 (in Japanese)

6. M. Pierantoni, M. Gremaud, P. Magnin, D. Stoll and W. Kurz : The Coupled Zone of Rapidly Solidified Al-Si Alloys in Laser Treatment, Acta Metall. Mater., 40 (7) (1992), 1637-1644

7. N. Apaydin and R. W. Smith : Microstructural Characterization of Rapidly Solidified Al-Si Alloys, Materials Science and Engineering, 98 (1988), 149-152 